\title{
The Effect of Carbide Morphologies on Elevated Temperature Tensile and Fatigue Behavior of a Modified Single Crystal Ni-Base Superalloy
}

\author{
A.J Wasson ${ }^{1}$ and G.E. Fuchs ${ }^{1}$ \\ ${ }^{1}$ University of Florida; P.O. Box 116400; Gainesville, FL 32611, USA
}

Keywords: Fatigue, Carbide Morphology, Porosity, Crack Initiation, Single Crystal Superalloys

\begin{abstract}
Minor additions of various grain boundary strengthening elements to single crystal Ni-base superalloys have been shown to improve castability, but their effects on mechanical properties are not well understood. A comparative investigation of baseline CMSX-4 and variations modified with carbon, carbon and boron, and carbon and nitrogen has been performed. These modifications have been shown to form interdendritic MC-type carbides with different morphologies. Heat treatments resulted in the breakdown of some carbide structures into small, spherical carbide particles of similar composition to the as-cast features. Tensile and high cycle fatigue (HCF) testing was conducted at $850^{\circ} \mathrm{C}$. The three carbon-containing modifications showed lower tensile strength than the baseline due to cracking of carbides and greater porosity. Fatigue crack initiations for Un-HIPed specimens occurred at pores that were adjacent to carbides in the modifications, which in general had shorter lifetimes than the baseline. HIPing dramatically increased fatigue lifetimes for all variations. Removal of porosity resulted in crack initiations at carbides and highlighted differences in fatigue behavior for varying carbide morphologies. Script carbide networks observed in the carbon only modification exhibited significant cracking that initiated failure, limiting the fatigue lifetime. Blocky carbides in the carbon and nitrogen modification remained intact, which resulted in longer fatigue lifetimes. The intact carbides did experience de-cohesion from the $\gamma / \gamma^{\prime}$ matrix that showed signs of plastic deformation in the vicinity of carbides.
\end{abstract}

\section{Introduction}

As nickel-base superalloys have evolved over the years from polycrystalline to single crystal, certain elements designed to strengthen grain boundaries have become unnecessary and been removed from these systems. The recent re-introduction of carbon into single crystals, however, has been useful in reducing casting grain defects [1-4]. This improved castability is especially important for production of very large single crystal castings used in industrial gas turbines. Stray grains and freckles have been shown to form in these materials due to thermosolutal convection, and it is believed the formation of carbides can reduce the driving force for this problem to occur. Carbon (C) additions are also helpful in reducing oxide inclusions and surface scale [5]. In the event that stray grain formation does occur it has been proposed that the addition of $\mathrm{C}$, as well as hafnium (Hf) and boron (B), may form grain boundary strengthening precipitates [6]. An understanding of the how these additions alter alloy characteristics will be useful in the ongoing modifications of these materials.

Castability improvements due to carbon additions have been linked to several key observations. The formation of carbides has been reported to reduce the amount of solidification segregation in model $2^{\text {nd }}$ generation superalloys, thereby minimizing the likelihood of convective instabilities [4]. Other recent findings showed no changes in partitioning behavior when carbon additions were added to an experimental $3^{\text {rd }}$ generation superalloy. In this case, the reduction is casting defect formation has been attributed to the physical presence of carbides in the interdendritic region blocking thermosolutal fluid flow [1]. This theory suggests that carbide morphology determines the effectiveness of reducing grain defect formation through minor carbon additions.

Recent work with CMSX-4, a common $2^{\text {nd }}$ generation alloy, found that additions of $\mathrm{B}$ and nitrogen $(\mathrm{N})$ along with $\mathrm{C}$ altered carbide morphologies in the as-cast state [7]. Morphology differences were associated with different carbide formation heights in the mushy zone during solidification that determined how freely the carbides could grow in the interdendritic region. Grain boundary element additions lower solidus temperatures and form brittle phases that can initiate cracking. When making such modifications in single crystal alloys, it is important to study how these elemental additions and carbide morphology changes influence heat treatment and mechanical response.

This investigation focuses on the heat treatment response of three carbon-containing CMSX-4 modifications and how the resulting microstructures impact high cycle fatigue (HCF) and elevated temperature tensile properties. Most mechanical property studies of carbon-modified monocrystal superalloys have focused on creep properties $[3,4,8,9]$. A few fatigue studies have shown fatigue crack initiation at pores and carbides, but no clear connections have been made between carbide morphology and fatigue failures $[10,11]$. The goal of this study is help further understanding of the role carbides play in HCF behavior of modified single crystal superalloys.

\section{Experimental Procedure and Materials}

The four alloy variations in this investigation were cast in bar form from a single master heat of CMSX-4 (Ni-9.6Co-6.5Cr6.4W-2.9Re-6.5Ta-6.0Al-1.0Ti-0.10Hf wt.\%) at PCC Airfoils in Minerva, Ohio. The minor alloying modifications were as follows: carbon $(\mathrm{C})$ only, carbon and boron $(\mathrm{C}+\mathrm{B})$, and carbon and nitrogen $(\mathrm{C}+\mathrm{N})$. All of the additions were made just prior to pouring. Graphite powder, boron powder, and $\mathrm{CrN}$ powder in the appropriate amounts were wrapped in Ni-foil and added to the melt to obtain the desired compositions. Alloy modifications are represented in Table I. All of the bars were cast using the Bridgman technique in the [001] orientation. The bars measured $12.5 \mathrm{~cm}$ in length with a diameter of $1.25 \mathrm{~cm}$. Laue back reflection confirmed orientation, and macroetching revealed any surface casting defects.

All of the bars underwent heat treatments at the University of Florida. The standard commercial solution heat treatment (SHT) for CMSX-4 was modified to achieve more complete 


\begin{tabular}{|l|c|l|l|l|l|l|}
\hline \multirow{2}{*}{$\begin{array}{l}\text { CMSX-4 } \\
\text { Variation }\end{array}$} & \multicolumn{2}{|c|}{ Carbon (wt.\%) } & \multicolumn{2}{l|}{ Boron (wt.\%) } & \multicolumn{2}{l|}{ Nitrogen (wt.\%) } \\
\cline { 2 - 7 } & aim & actual & aim & actual & aim & actual \\
\hline Baseline & 0.000 & 0.002 & trace & 0.0004 & trace & 0.0002 \\
\hline C only & 0.050 & 0.066 & trace & 0.0011 & trace & 0.0003 \\
\hline C + B & 0.050 & 0.063 & 0.005 & 0.0068 & trace & 0.0003 \\
\hline C + N & 0.050 & 0.063 & trace & 0.0011 & 0.0025 & 0.0025 \\
\hline
\end{tabular}

Table I. Compositions of CMSX-4 modifications.

\begin{tabular}{|l|l|}
\hline Solution & $\begin{array}{l}1280^{\circ} \mathrm{C} / 2 \mathrm{hr} \rightarrow 1296^{\circ} \mathrm{c} / 2 \mathrm{hr} \rightarrow 1310^{\circ} \mathrm{C} / 2 \mathrm{hr} \rightarrow 1318^{\circ} \mathrm{C} / 2 \mathrm{hr} \rightarrow 1322^{\circ} \mathrm{C} / 2 \mathrm{hr} \\
\rightarrow 1325^{\circ} \mathrm{C} / 4 \mathrm{hr} / \mathrm{Gas} \text { Furnace Quench }\end{array}$ \\
\hline $\begin{array}{l}\text { Partial } \\
\text { Solution }\end{array}$ & $1200^{\circ} \mathrm{C} / 10 \mathrm{~min} \rightarrow 1280^{\circ} \mathrm{C} / 1 \mathrm{hr} \rightarrow 1325^{\circ} \mathrm{C} / 1 \mathrm{hr} /$ Gas Furnace Quench \\
\hline Age & $1140^{\circ} \mathrm{C} / 6 \mathrm{hr} /$ Air Cool $+871^{\circ} \mathrm{C} / 20 \mathrm{hr} /$ Air Cool \\
\hline
\end{tabular}

Table II. Heat treatment schedule. All variations were given the solution heat treatment and the age heat treatment. HIPed bars were given the partial solution heat treatment after HIPing and before aging.

homogenization and to eliminate $\gamma / \gamma^{\prime}$ eutectics. The SHT was done in a vacuum furnace to minimize surface oxidation and included a forced helium quench with a cooling rate of $100^{\circ} \mathrm{C} / \mathrm{min}$. The multi-step SHT is shown in Table II. Following solutioning, the bars were subjected to a two-step age heat treatment: $1140^{\circ} \mathrm{C} / 6 \mathrm{hrs}$./air cool followed by $871^{\circ} \mathrm{C} / 20 \mathrm{hrs} . / \mathrm{air}$ cool.

Prior to the age heat treatments, one batch of bars was hot isostatically pressed (HIPed). This process involves the application of hydrostatic pressure by an inert gas at elevated temperature to collapse pores. HIP treatments have been reported to be very successful at reducing or eliminating casting porosity in Ni-base superalloys [12-15]. The goal of HIPing in this study was to reduce potential crack initiation sites in order to highlight carbide morphology effects. After the HIP treatment, the bars underwent a partial solution to re-homogenize. The HIPed batch then went through the same age heat treatments as the Un-HIPed batch as described previously.

Each heat treated bar was machined into two cylindrical test specimens at Joliet Metallurgical Labs in Joliet, Illinois. A low stress grinding technique was used to avoid inducing unwanted stresses into the specimens. All specimens had gage diameters near $4.55 \mathrm{~mm}$ and gage lengths near $26 \mathrm{~mm}$. Each specimen was carefully measured. Fatigue specimen gage sections required surface polishing with progressively finer grit paper to create a smooth finish. This was done to avoid external crack initiations in order to isolate the effect of internal microstructural features on fatigue behavior.

Elevated temperature tensile testing was performed on Un-HIPed specimens using a Satec servo-hydraulic tensile machine. A clamshell furnace was used to heat the samples to $850^{\circ} \mathrm{C}$, and two thermocouples were attached directly to the gage section of the sample to monitor temperature. One of the thermocouples controlled the furnace and the other thermocouple was used for verification. An initial strain rate of $2.54 \mathrm{~cm} / \mathrm{min}$. was employed.

High cycle fatigue tests were performed using the same servohydraulic machine as the tensile tests with the same method for temperature control. Fatigue conditions were as follows:

Load control

$$
\begin{aligned}
& \mathrm{T}=850^{\circ} \mathrm{C} \\
& \Delta \sigma=690 \mathrm{MPa}
\end{aligned}
$$

stress ratio $\mathrm{R}=0.1$, tension-tension triangular waveform frequency $=20 \mathrm{~Hz}, 15 \mathrm{~Hz}$

Five rounds of HCF testing were conducted. Each round consisted of one test each of baseline CMSX-4 and the three modifications for an overall total of $20 \mathrm{HCF}$ tests. The first three rounds tested Un-HIPed specimens and the last two rounds involved samples that had undergone HIP. The $20 \mathrm{~Hz}$ frequency was only used for the first round of testing and $15 \mathrm{~Hz}$ frequency testing was utilized for all subsequent testing.

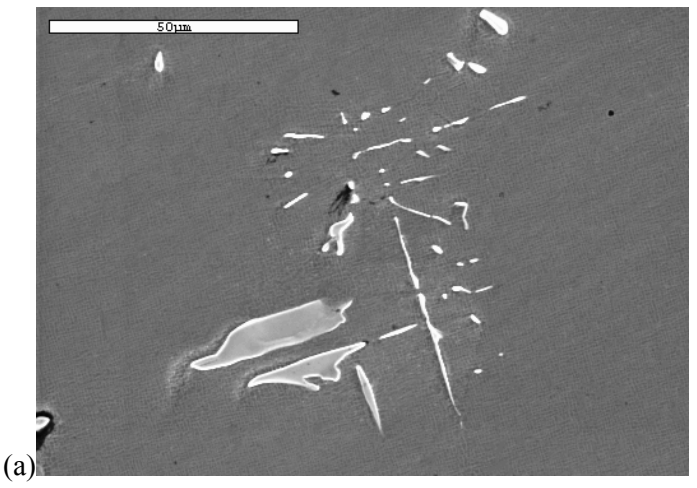

(b)

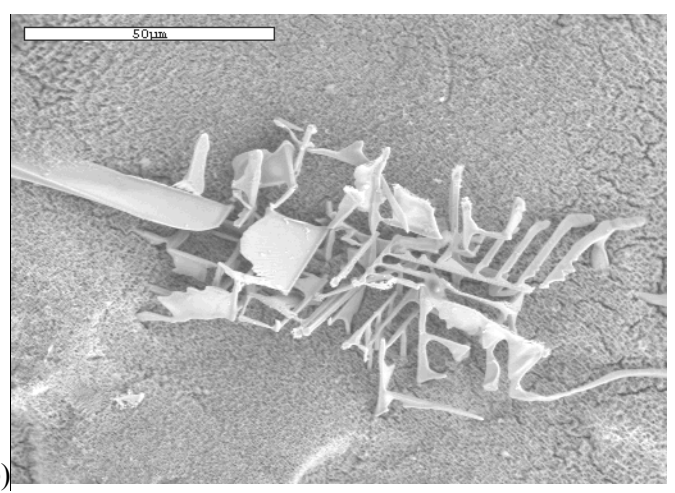

Figure 1. SEM micrographs of carbides in the (a) light-etched condition and (b) deep-etched condition. 
Standard grinding and polishing using silicon carbide paper and alumina slurry suspensions was performed on as-cast, heat treated, and post-test samples. A Pratt \& Whitney $\gamma^{\prime}$ etchant revealed standard microstructural features such as eutectics and carbides. Imaging of carbide phases only in light-etched, flat cross-sections can lead to misunderstandings of true morphology. A carbide network with an array of cylindrical rods appears as a group of small, discrete round particles when viewed in cross-section. Therefore, a deep etch containing hydrochloric acid and hydrogen peroxide was also used to reveal carbide morphologies. A comparison of carbide appearance using each of the etchants is shown in Figure 1.

All etched samples and fracture surfaces were examined with a JEOL 6400 Scanning Electron Microscope (SEM) at the University of Florida Major Analytical Instrumentaton Center. Energy dispersive spectroscopy (EDS) was used for semiquantitative analysis of carbides. More precise carbide compositional data was collected from polished, unetched samples using wavelength dispersive spectroscopy (WDS) on a JEOL 733 Superprobe.

\section{Results}

\section{$\underline{\text { Microstructure }}$}

As previously reported, the carbon-containing modifications did not significantly affect as-cast $\gamma / \gamma^{\prime}$ microstructure or solidification segregation, but the modifications did result in the reduction of volume fraction eutectic and increased casting porosity [7]. Ascast carbide morphologies for the three modifications are shown in Figure 2. The $\mathrm{C}$ addition as well as the $\mathrm{C}+\mathrm{B}$ addition produced carbides that formed in interdendritic script-like networks consisting of connected rods and plates. Some regions consisted of parallel arrays of rods that had partially "filled-in" in an incomplete plate formation during solidification. Cores of the networks were between primary dendrite arms and carbide rods branched off of the cores in between secondary dendrite arms. The $\mathrm{C}+\mathrm{N}$ modification exhibited interdendritic, blocky carbides that showed less spatial orientation in relation to the dendrites than the script networks found in the other two carbon containing modifications. All as-cast carbides analyzed were Ta-rich, MCtype primary carbides.

Solution heat treatment successfully eliminated the majority of eutectic in all four variations. Carbide compositions remained Tarich, and post-SHT carbide networks in the $\mathrm{C}$ and the $\mathrm{C}+\mathrm{B}$ modifications Were largely unchanged. Slight surface changes were observed on the faces of blocky carbides in the $\mathrm{C}+\mathrm{N}$ modification That appeared to be early stages of degeneration into smaller carbide particles, example shown in Figure 3.

The two-step aging heat treatment produced the desired $\gamma / \gamma^{\prime}$ structure with $\gamma^{\prime}$ precipitates of size on the order of 0.3-0.5 $\mu \mathrm{m}$. The $\mathrm{C}+\mathrm{B}$ variant Had a fully-aged structure that was slightly different than the other three modifications. After aging, some of the script networks had transformed into smaller, more rounded carbide particles. This morphology change occurred more in the $\mathrm{C}+\mathrm{B}$ variant Than in the $\mathrm{C}$ variant. These small, spherical particles were also observed in the $\mathrm{C}+\mathrm{N}$ modification nearby characteristic blocky carbides. Carbide compositions for all morphologies did not change as a result of heat treatment. A representative EDS spectrum is shown in Figure 4.

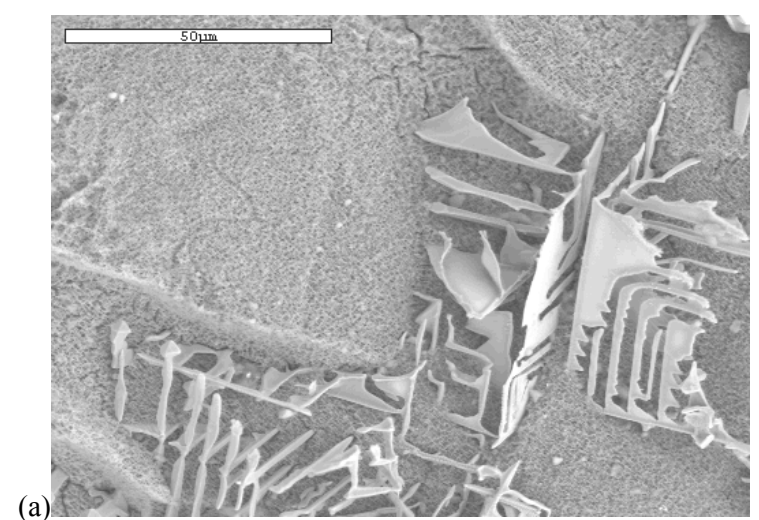

(b)
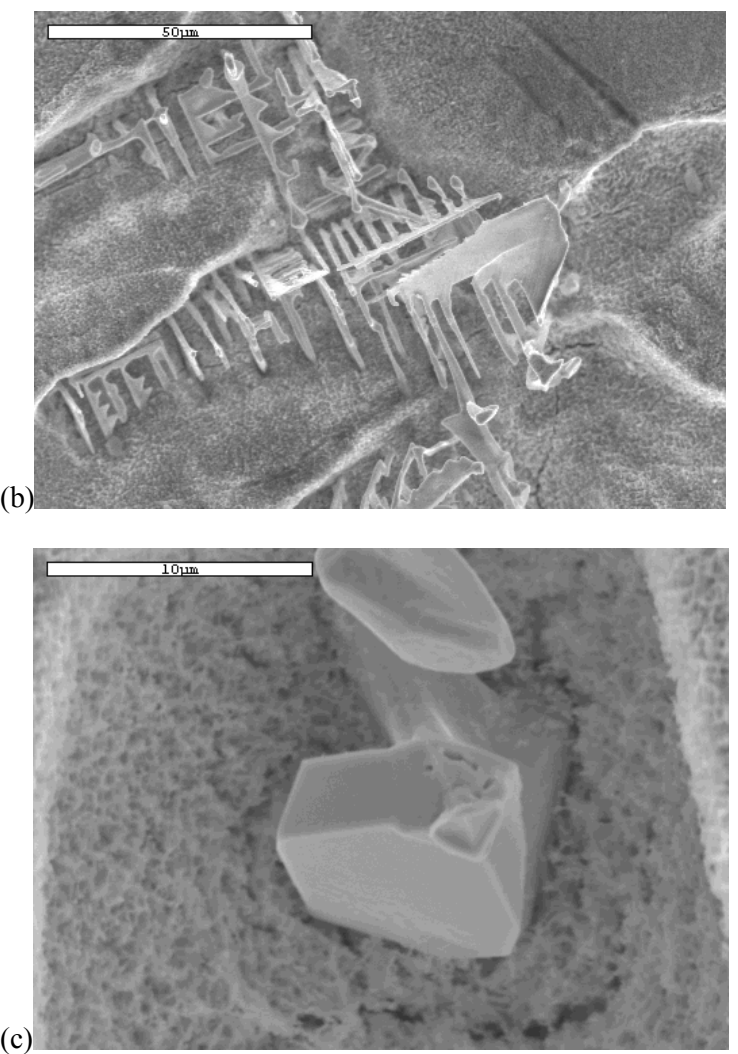

Figure 2. SEM micrographs of as-cast carbide morphologies in modified CMSX-4 alloys: (a) $\mathrm{C}$ addition, (b) $\mathrm{C}+\mathrm{B}$ addition, and (c) $\mathrm{C}+\mathrm{N}$ addition.

\section{$\underline{\text { Tensile Testing }}$}

The ultimate tensile strength at $850^{\circ} \mathrm{C}$ of baseline CMSX-4 was higher than all three carbon-containing variants, as shown in Table III. Tensile tests were only conducted on Un-HIPed specimens.

Fracture surfaces of the modified alloys contained rough, faceted steps indicative of cleavage-type fracture, while the facets seen in 


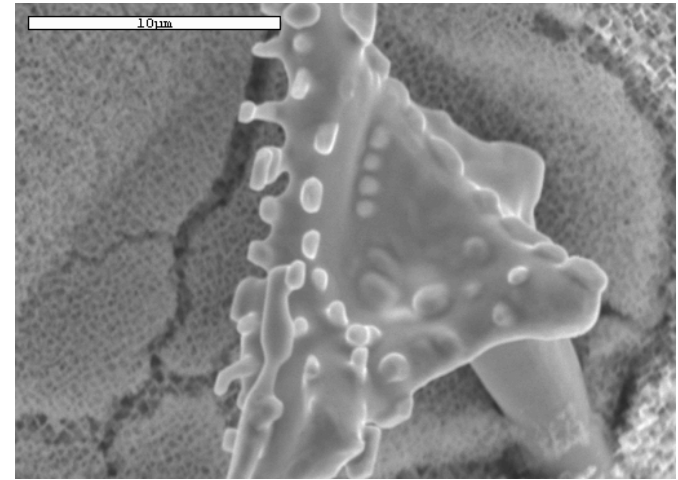

Figure 3. SEM micrograph of a carbide in the $\mathrm{C}+\mathrm{N}$ modification after SHT.

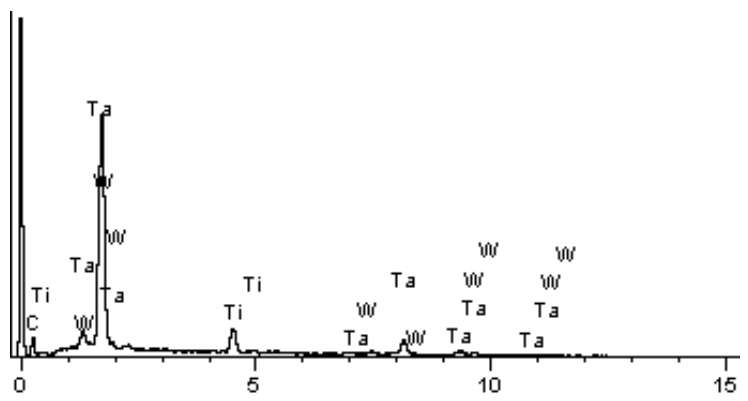

Figure 4. EDS spectrum of Ta-rich carbide after full heat treatment

\begin{tabular}{|c|c|}
\hline Variation & UTS (MPa) \\
\hline Baseline & 1201.6 \\
\hline C only & 1151.2 \\
\hline$C+B$ & 1142.9 \\
\hline$C+N$ & 1110.2 \\
\hline
\end{tabular}

Table III. Measured tensile strengths of all 4 variations at $850^{\circ} \mathrm{C}$.

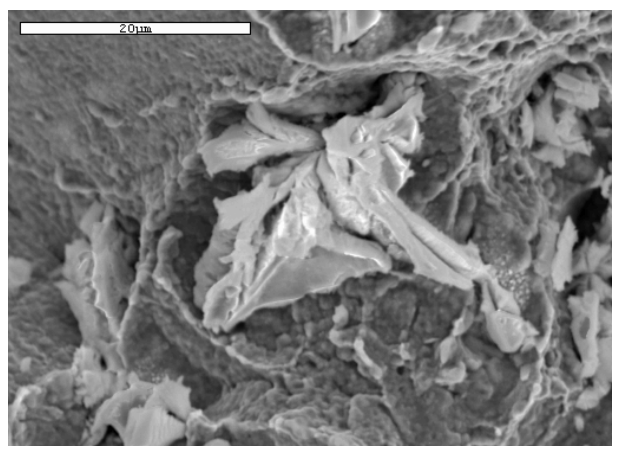

Figure 5. SEM image of a broken carbide on the tensile fracture surface of a $\mathrm{C}+\mathrm{N}$ modified specimen.

the baseline alloy were smoother in nature. Cracked carbides, as seen in Figure 5, were observed and were often in the immediate vicinity of pores. Longitudinal sections revealed evidence of cracks perpendicular to the loading axis, which were accompanied by carbide cracks in the three modified alloys. Figure 6 illustrates such a case.

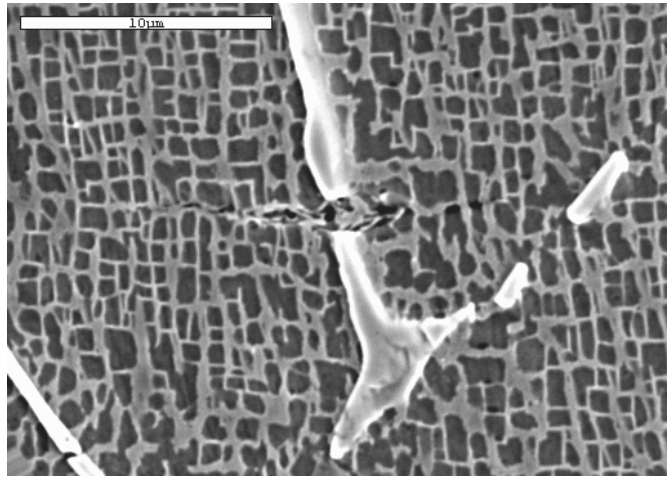

Figure 6. Longitudinal SEM image of matrix and carbide crack in $\mathrm{C}+\mathrm{B}$ modified tensile sample. Stress direction is vertical.

\section{High Cycle Fatigue}

Three samples of each variation were tested in HCF in the UnHIPed condition at $850^{\circ} \mathrm{C}$. The fatigue lifetimes $\left(\mathrm{N}_{\mathrm{f}}\right)$ are represented in Figure 7a. The large amount of scatter is to be expected when dealing with HCF lifetimes [10]. Baseline alloy specimens generally had higher cycles to failure than the carboncontaining samples. One exception was a $\mathrm{C}+\mathrm{B}$ modified sample with a lifetime of 674,213 cycles, the highest of any of the UnHIPed trials. Fracture surfaces were very similar for all HCF samples in this condition. Crack initiation was observed to occur at internal pores, which were associated with carbides in the modified variations as seen in Figure 8a. Large, elliptical or semielliptical crack growth planes radiated from initiation sites. Macroscopically, these initiation zones appeared smooth and reflective. Crack growth occurred in a direction perpendicular to the axis of loading for all modifications and all but 1 of the 3 baseline specimens. The baseline sample with the shortest lifetime $(295,457$ cycles) exhibited a shear fracture surface on a plane approximately $45^{\circ}$ to the stress direction. Crack initiation and growth was confined to this plane. Transitions between areas of crack growth and overloaded regions were clearly visible for all samples. Overloaded regions were similar to the high temperature tensile fracture surfaces described earlier. Longitudinal posttested sections revealed: regions of porosity near carbides in the modifications, some carbides that were cracked normal to the load direction, and signs of some deformed $\gamma / \gamma^{\prime}$ structure in the vicinity of carbides. Crack propagation occurred in a direction perpendicular to the load axis or in zigzagged crack paths approximately $50^{\circ}$ from the load axis as seen in Figure $8 \mathrm{~b}$.

HIPing had a positive effect on the fatigue behavior of baseline CMSX- 4 and the variants. The fatigue lifetimes for the 8 HIPed samples are shown in Figure $7 \mathrm{~b}$. The HIPing process improved HCF lifetimes for all alloy modifications. One baseline specimen lasted nearly 7 million cycles before failure and the other only about 742,208 cycles. This large data spread is likely due to the abnormally large pore, approximately 40 microns in diameter, that was identified as the initiation site for the shorter lifetime sample. It was unclear how such a large pore was present after HIPing. The initiating pore size for the longer lifetime baseline specimen was approximately 10 microns. This kind of spread was not seen in the 3 modifications. The $\mathrm{C}+\mathrm{N}$ modification benefited the 
most from the HIP process, experiencing a near order of magnitude increase in fatigue life, followed by the $\mathrm{C}+\mathrm{B}$ variant and the $\mathrm{C}$ modification. $\mathrm{HCF}$ fracture surfaces of HIPed specimens revealed crack initiations at pores in the baseline alloy and at carbides in the modifications. Both $\mathrm{C}$ modification initiations occurred at large clusters of cracked carbides, while one $\mathrm{C}+\mathrm{N}$ modification initiation was at a smaller, specific carbide and the other at the specimen surface. The shorter lifetime $\mathrm{C}+\mathrm{B}$ specimen showed crack initiation similar to $\mathrm{C}$ variant, and in the longer lifetime specimen initiation occurred at a specific carbide.

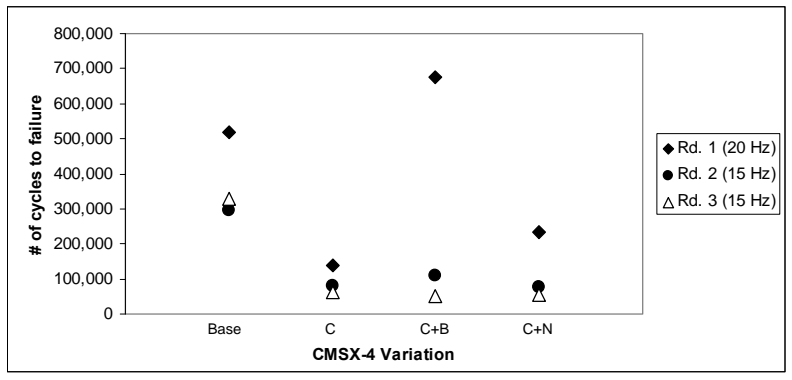

(a)

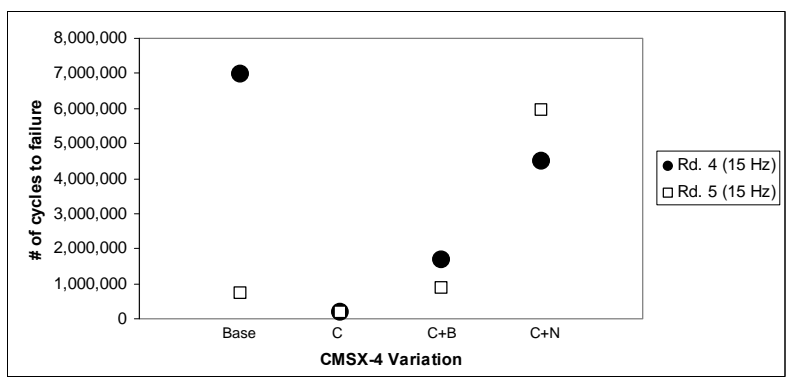

(b)

Figure 7. $\mathrm{HCF}$ lifetimes at $850^{\circ} \mathrm{C}$ in the (a) Un-HIPed and (b) HIPed condition.

Carbide crack initiation sites showed no porosity. Typical crack initiations are shown in Figure 9. Crack growth zones radiated elliptically from initiation sites as in the Un-HIPed case, but the growth areas were much smaller and not always perpendicular to the load axis. Longitudinal sections of HIPed test specimens had very few signs of porosity, but did display some of the other features seen in Un-HIPed samples. A large percentage of thin carbide plates and rods pointing in the stress direction featured numerous cracks across their thin cross sections as seen in Figure 10a. This cracking was most evident in the abundant script networks of the $\mathrm{C}$ modification. Blocky carbides in the $\mathrm{C}+\mathrm{N}$ modified alloy remained largely un-cracked, but some displayed de-cohesion from the surrounding matrix as seen in Figure $10 \mathrm{~b}$. The $\mathrm{C}+\mathrm{B}$ variant contained some carbides with cracks and some that experienced de-cohesion, but the small, spherical carbides resulting from heat treatment did not exhibit either behavior. The $\gamma / \gamma^{\prime}$ matrix near carbides in all modifications was more deformed than similar areas in the Un-HIPed samples. Matrix cracks, as shown in Figure 10c, appeared either at these areas of localized deformation or at cracked carbides.

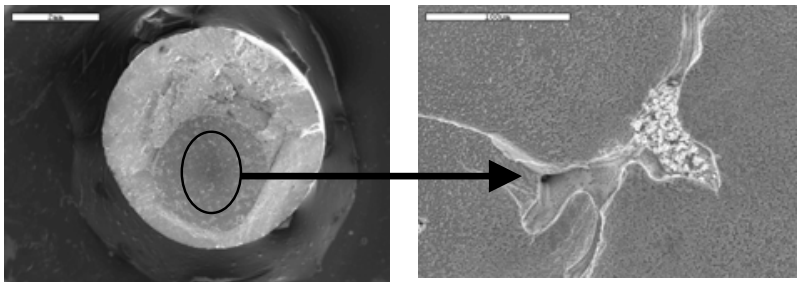

(a)

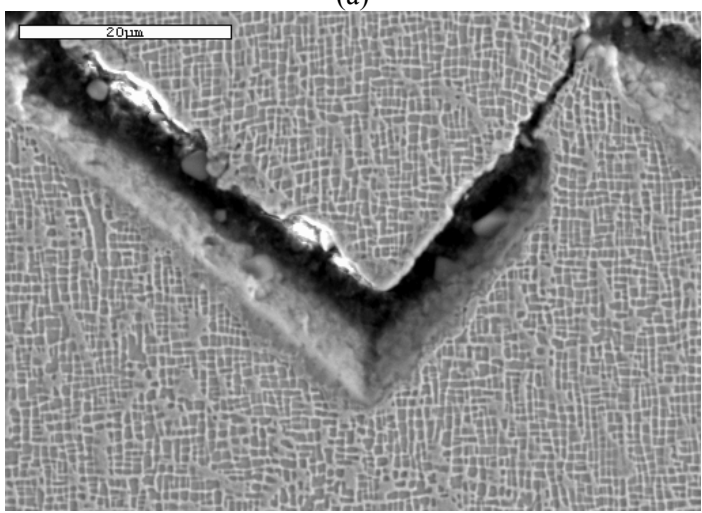

(b)

Figure 8. SEM images of (a) characteristic crack initiation site on fracture surface and (b) a zigzagged crack path in a longitudinal section for Un-HIPed HCF specimens.

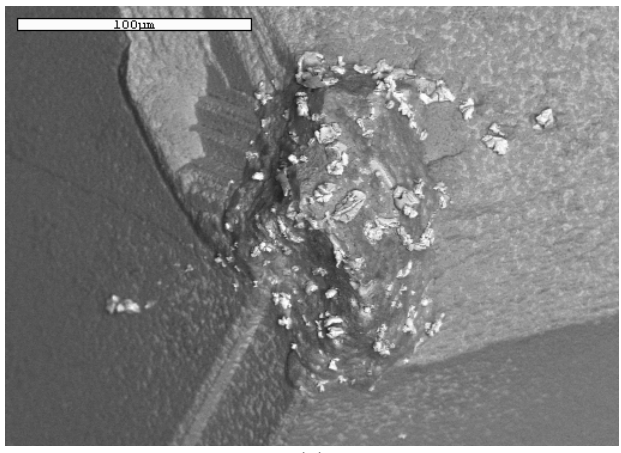

(a)

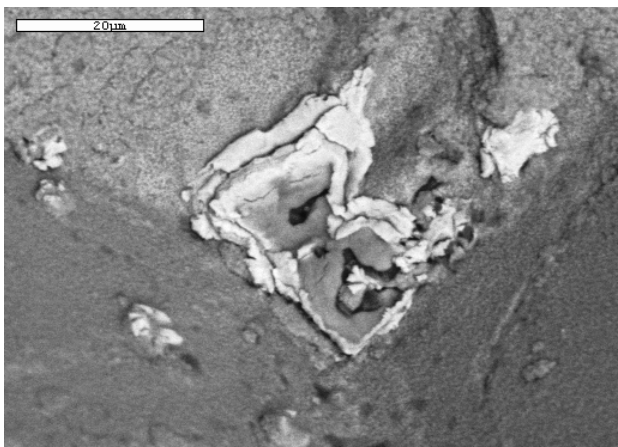

(b)

Figure 9. BSE images of fatigue crack initiation sites in HIPed HCF samples: (a) cluster of broken carbides in $\mathrm{C}$ modification and (b) distinct carbide in $\mathrm{C}+\mathrm{N}$ modification. 

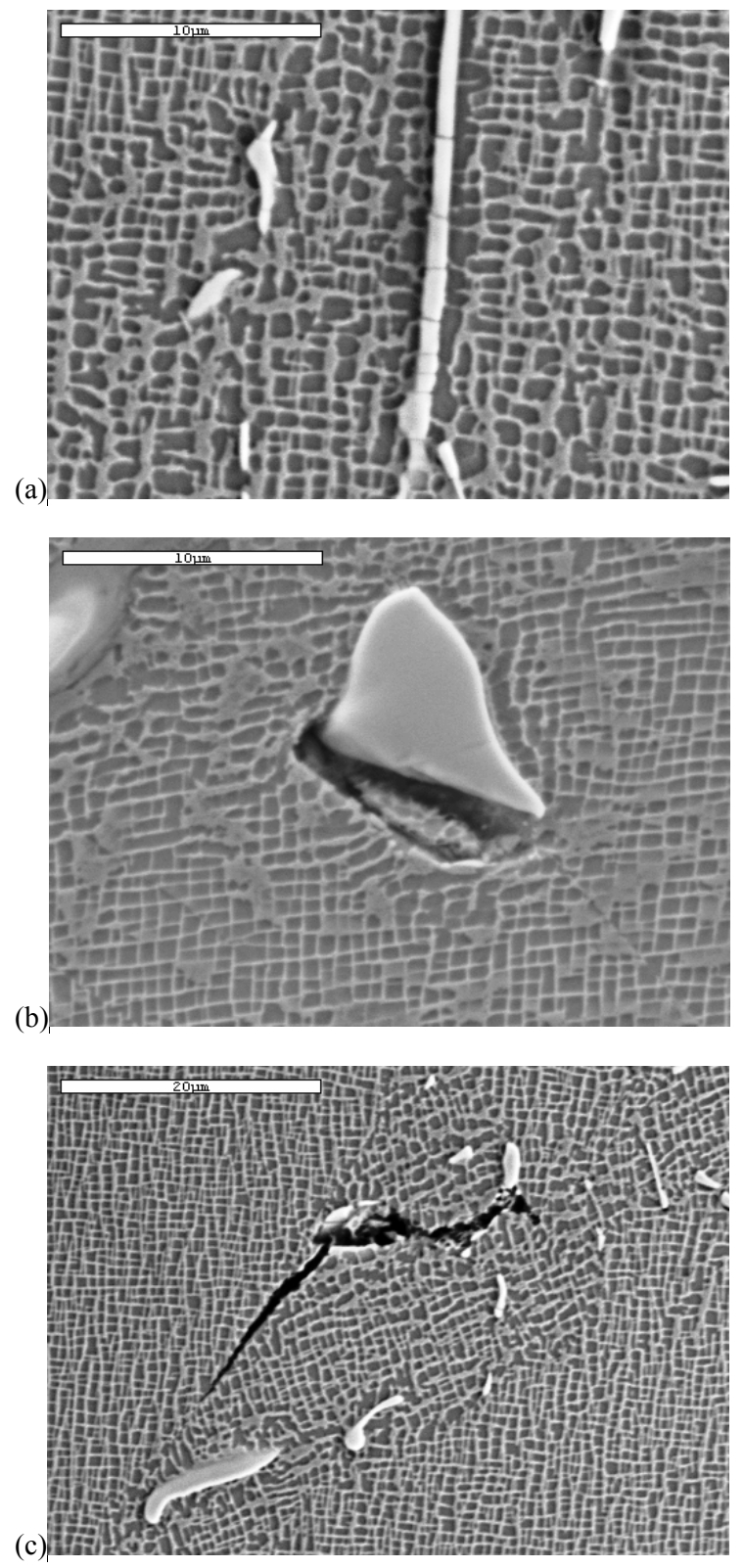

Figure 10. SEM images of HCF longtidinal sections in the HIPed condition showing (a) carbide cracking in $\mathrm{C}$ variant, (b) carbide decohesion in $\mathrm{C}+\mathrm{N}$ variant, and (c) matrix crack near deformed $\gamma / \gamma^{\prime}$. Stress direction is vertical.

\section{Discussion}

\section{$\underline{\text { Microstructure }}$}

The reasons for the dramatic difference in carbide morphology when a minor addition of nitrogen was present are not entirely clear. The nitrogen containing alloy had a lower carbide solvus temperature than the carbon only alloy, which suggests the blocky morphology observed was not due to carbide formation higher in the mushy zone. The difference in morphology may be due to surface energy considerations resulting from small compositional differences of the carbide and liquid in the mushy zone. A higher surface energy leads to a higher driving force for reducing overall surface area by forming blockier structures.

No changes in carbide composition after heat treatment were observed in any of the modificaitons even when the carbide morphology was observed to change. Recent work has reported decomposition of primary carbides into secondary carbides such as $\mathrm{M}_{23} \mathrm{C}_{6}$-type and $\mathrm{M}_{6} \mathrm{C}$-type due to heat treatment of similar alloy systems $[3,11]$. Another recent study, however, found Ta-rich MC carbides remained stable during heat treatment [9]. This stability was attributed to the presence of $4.2 \mathrm{wt} . \%$ Re in the alloy restricting formation of $\mathrm{M}_{6} \mathrm{C}$ carbides. The Re in CMSX-4 may account for the lack of carbide decomposition seen in the present study.

Degeneration of carbide into small, round particles was observed in the modified alloys. Blocky carbides in the $\mathrm{C}+\mathrm{N}$ modification showed evidence of changing morphology due to SHT, as seen in Figure 3. Overall surface energy is reduced when a change from a blocky to a spherical shape occurs. It would be expected that this morphology change would be seen also in the script carbide networks. Smaller particles were seen in the post-aging microstructure, but not in the post-SHT condition. It is possible that some of script rods and plates were transforming, but the evidence may have been more difficult to observe in the networks than on the flat facets of the $\mathrm{C}+\mathrm{N}$ variant blocky structures.

Spherical carbide particles were observed more commonly in fully heat treated $\mathrm{C}+\mathrm{B}$ modification than in the $\mathrm{C}$ modification, which retained more script networks. There are several possible explanations for this behavior. Differential Thermal Analysis (DTA) showed the addition of $\mathrm{C}+\mathrm{B}$ reduced the as-cast solidus of CMSX-4 from $1319^{\circ} \mathrm{C}$ to $1316^{\circ} \mathrm{C}$ as compared to a reduction due to the addition of $\mathrm{C}$ only to $1318^{\circ} \mathrm{C}$ [7]. The $\mathrm{C}+\mathrm{B}$ modification is closer to its solidus temperature during heat treatment, which can lead to incipient melting. Incipient melting was not seen in this study, but it is likely more diffusion occurred in the $\mathrm{C}+\mathrm{B}$ variant at the heat treatment temperatures. Higher diffusion rates may have led to more transformation to spherical carbide particles. Another possible explanation involves potential lattice misfit differences. Recent work with a $2^{\text {nd }}$ generation superalloy modified with $\mathrm{C}, \mathrm{B}$, and $\mathrm{Hf}$ reported that differences in lattice misfit caused different $\mathrm{MC}$ carbide morphologies [8]. The carbide lattice parameter for one of the modified alloys was greater due to a higher concentration of $\mathrm{Hf}$ in the carbide. The larger misfit between carbide and matrix was reported to cause a more block-shape morphology with less surface area. In the present study, differences in carbide lattice parameters may help explain how the $\mathrm{C}+\mathrm{B}$ modification experiences more degeneration than the $\mathrm{C}$ modification. Larger misfit may lead to a higher driving force for reducing surface area by changing from script networks to spherical particles.

\section{$\underline{\text { Tensile Testing }}$}

The carbon-containing variants had lower ultimate tensile strengths at $850^{\circ} \mathrm{C}$ than baseline CMSX-4. Carbide phases could provide strengthening by acting as obstacles for dislocations, but this is counteracted by their brittle nature that leads to cracking. As seen in Figure 6, cracking of carbides during testing directly caused $\gamma / \gamma^{\prime}$ matrix cracks. This kind of coupled carbide/matrix cracking was observed for all carbide morphologies in all three 
modified alloys. The presence of these crack nucleation sites leads to lower ultimate tensile strengths in the modifications. Porosity may also be a factor in explaining the lower tensile strengths. The Un-HIPed modifications that were tested in tension had higher porosity volume fractions than the baseline, and it has been shown that microporosity has a negative effect on mechanical properties $[7,14]$.

\begin{tabular}{|cc|}
\hline Variation & Av. Pore Area $\left(\boldsymbol{\mu m}^{2}\right)$ \\
Baseline & 78 \\
C only & 164 \\
C + B & 121 \\
C + N & 171 \\
\hline
\end{tabular}

Table IV. Average elliptical pore areas observed on tensile fracture surfaces.

Elliptical pores observed on tensile fracture surfaces were measured for comparison by determining major and minor axes and using the generalized formula for the area of an ellipse. Average elliptical areas for each of the 4 tensile fracture surfaces are shown in Table IV. The largest average pore size belonged to the $\mathrm{C}+\mathrm{N}$ variant, which also exhibited the lowest tensile strength. It was determined that the lower tensile strengths for the modified alloys can be attributed to cracking of carbides as well as higher levels of porosity compared to baseline CMSX-4.

\section{High Cycle Fatigue}

Porosity was the controlling factor for HCF crack initiation in UnHIPed specimens, and carbide morphology determined crack initiation behavior for the modified HIPed alloys. The dramatic increases in fatigue life by HIPing indicate that reduction in porosity improves fatigue performance, a result that supports past work with CMSX-4 [13].

\section{Un-HIPed}

Pores have been reported as common crack initiation sites in fatigue studies of single crystal superalloys without carbon additions [16, 17]. Of interest in the current study is that the initiating pores in the modifications were directly adjacent to carbides. In most cases broken carbide pieces were visible "inside" of the initiating pores (Figure 8a). This observation supports previous work that reported carbides block molten flow during the final stages of solidification to increase porosity [1]. This flow blockage causes pores to form in the immediate vicinity of carbides. As-cast and heat-treated microstructures also revealed pores away from carbides, but it was the porosity at carbides that initiated failures.

The sizes of failure causing pores were measured for the $12 \mathrm{Un}$ HIPed HCF tests and plotted vs. corresponding fatigue lifetimes. The results are shown in Figure 11. In general, smaller initiating pore sizes are observed for trials with higher fatigue lifetimes. Baseline specimens exhibited both the smallest initiating pore sizes and longest lifetimes. The trend seen in these results agrees with other recent work comparing failure causing pore sizes to fatigue lifetimes [10].

Less plastic deformation near carbides was observed in the UnHIPed longitudinal sections than in the HIPed condition. This kind of deformation likely increases as more stress cycles are applied to the sample. Due to the shorter lifetimes seen in the UnHIPed case, fatigue failures due to porosity occurred before large amounts of plastic deformation developed.

\section{HIPed}

Pores served as crack initiation sites only for the baseline HIPed specimens. The lifetimes displayed a correlation with initiating pore size once again as mentioned previously. The large initiating pore observed in the shorter lifetime baseline sample indicates that the HIPing treatment did not completely minimize porosity for that sample.

Differences in carbide morphology controlled crack initiation behavior in the modified HIPed HCF tests. Both $\mathrm{C}$ modification tests and the shorter lifetime $\mathrm{C}+\mathrm{B}$ modification test failed due to initiations at groups of broken carbides (Figure 9a). These initiation sites were significantly larger than the discrete carbide initiations seen in one of the $\mathrm{C}+\mathrm{N}$ modification tests and the longer lifetime $\mathrm{C}+\mathrm{B}$ modification trial. A large number of cracked carbide rods and plates were observed in longitudinal sections of the $\mathrm{C}$ modified alloy samples. It is most likely that cracking of script-like carbide networks coupled with plastic deformation near the networks triggered crack initiations earlier than in the other modifications. Earlier initiation of cracks led to relatively short lifetimes for the $\mathrm{C}$ modification HIPed condition.

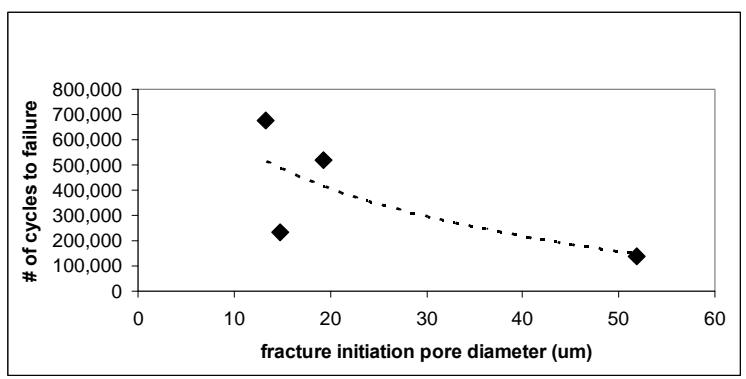

(a)

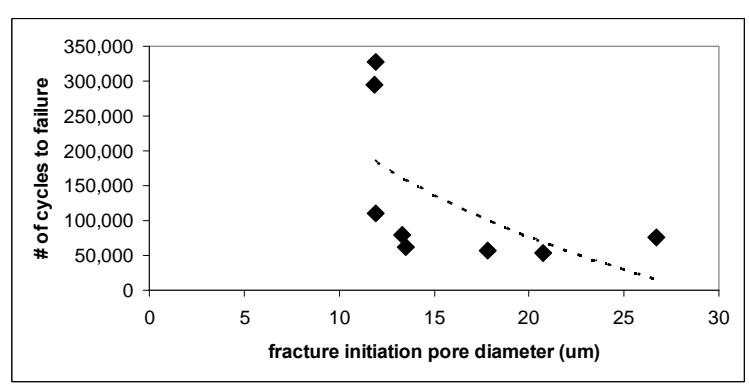

(b)

Figure 11. Failure initiating pore size vs. number of cycles to failure for Un-HIPed HCF tests, (a) $20 \mathrm{~Hz}$ tests and (b) $15 \mathrm{~Hz}$ tests.

Blocky carbides in the $\mathrm{C}+\mathrm{N}$ variant resulted in longer fatigue lifetimes. The $\mathrm{C}+\mathrm{N}$ modified sample with a lifetime near 4.5 million cycles featured a crack initiated at a discrete carbide (Figure 9b). The other $\mathrm{C}+\mathrm{N}$ modified sample exhibited a surface crack initiation and had a lifetime of nearly 6 million cycles. $\mathrm{C}+$ $\mathrm{N}$ modified longitudinal sections revealed blocky carbides that were intact with significant levels of plastic deformation nearby. 
Some of the carbides had pulled away from the matrix (Figure 10b). Therefore, it appears that when cyclic stresses acted on the specimen without causing carbide cracking a significant level of local deformation formed near carbides, which continued to accumulate until carbide de-cohesion from the matrix occurred. This de-cohesion, along with deformation in the vicinity, could initiate a crack that would grow until causing failure. The $\mathrm{C}+\mathrm{B}$ modification displayed carbide morphology intermediate to script and blocky, and the fatigue lifetimes also fell in between the other two modifications.

There appears to be competing fatigue crack initiation mechanisms at work in the alloys investigated. For all Un-HIPed alloys and the baseline HIPed condition, pore size is the primary factor controlling initiation. Carbide morphology effects are evident in the HIPed modified alloys, where initiations due to cracked carbides occur earlier than initiations due to carbide/matrix de-cohesion. Plastic deformation near carbides seems to play a role in both of these mechanisms. Surface crack initiation can also occur due to a surface flaw or slip-band extrusion and intrusion ridges.

\section{Conclusions}

- Minor additions of boron and nitrogen, along with carbon, to CMSX-4 resulted in the formation of Ta-rich, MC-type interdendritic primary carbides of different morphologies. The carbides remained Ta-rich and MC-type even after changes in carbide morphologies occurred as a result of heat treatment.

- Higher porosity levels and larger pore sizes resulted in shorter high cycle fatigue lifetimes for carbon-containing CMSX-4 modifications than baseline CMSX-4 in the UnHIPed condition.

- HIPing significantly improved fatigue performance in all four variations. HIPing also isolated the effect of carbide morphology on fatigue crack initiation behavior. $\mathrm{C}+\mathrm{N}$ modified fatigue specimens featured de-cohesion of blocky carbides from the $\gamma / \gamma^{\prime}$ matrix and had longer fatigue lifetimes than $\mathrm{C}$ modified samples, which featured cracking of scriptlike carbide networks.

\section{Acknowledgements}

The material presented here is based on work supported by the National Science Foundation under Grant Nos. 0072671 and 0353952 .

The authors would like to thank the Major Analytical Instrumentation Center (MAIC) at the University of Florida for their assistance and support during the analysis of the alloys in this study. The authors also wish to thank PCC Airfoils in Ohio for the HIPing of bars. Tedi-Marie Usher, Jessica Register and the rest of the High Temperature Alloys Research Group are also thanked for their assistance with this work.

\section{References}

1. K.A. Al-Jarba and G.E. Fuchs, "Effect of Carbon Additions on the As-Cast Microstructure and Defect
Formation of a Single Crystal Ni-Based Superalloy," Mat. Sci. and Eng. A, 373 (2004), p. 255-267.

2. S. Tin, T.M. Pollock, and W.T. King, "Carbon Additions and Grain Defect Formation in High Refractory Nickel-Base Single Crystal Superalloys," Proc. Superalloys 2000. TMS. Seven Springs, PA: p. 201-210.

3. Liu, L.R., et al., "Formation of Carbides and Their Effects on Stress Rupture of a Ni-Base Single Crystal Superalloy," Mat. Sci. and Eng. A, 361 (2003), p. 191197.

4. S. Tin and T.M. Pollock, "Phase Instabilities and Carbon Additions in Single-Crystal Nickel-Base Superalloys," Mat. Sci. and Eng. A, 348 (2003), p. 111121.

5. Mihalisin, J.R., et al., "Some Effects of Carbon in the Production of Single Crystal Superalloy Castings," Proc. Superalloys 2004. TMS. Seven Springs, PA: p. 795-799.

6. Y.H. Kong and Q.Z. Chen, "Effects of Minor Additions on Microstructure and Creep Performance of RR2086 SX superalloys," Journal of Mat. Sci., 39 (2004), p. 6993-7001.

7. E.R. Cutler, A.J. Wasson, and G.E. Fuchs, "Effect of Minor Alloying Additions on the Carbide Morphology in a Single Crystal Ni-Base Superalloy," Scripta Mat., 58 (2008), p. 146-149.

8. Q.Z. Chen, N. Jones, and D.M. Knowles, "The Microstructures of Base/Modified RR2072 SX Superalloys and Their Effects on Creep Properties at Elevated Temperatures," Acta Mat., 50 (2002), p. 10951112 .

9. Yu, J., et al., "Effect of Heat Treatment on Microstructure and Stress Rupture Life of DD32 Single Crystal Ni-Base Superalloy," Mat. Sci. and Eng. A, 460-461 (2007), p. 420-427.

10. M. Lamm and R.F. Singer, "The Effect of Casting Conditions on High-Cycle Fatigue Properties of the Single-Crystal Nickel-Base Superalloy PWA 1483," Met. and Mat. Trans. A, 38A (2007), p. 1177-1183.

11. Yi, J.Z., et al., "Ultrasonic Fatigue of a Single Crystal Ni-Base Superalloy at $1000^{\circ} \mathrm{C}, "$ Mat. Sci. Eng. A, 443 (2007), p. 142-149.

12. R.A. Stevens and P.E.J. Flewitt, "Hot Isostatic Pressing to Remove Porosity and Creep damage," Mat. and Design, Vol. 3, Issue 3 (1982), p. 461-469.

13. Harris, K., et al., "Development of Two RheniumContaining Superalloys for Single-Crystal Blade and Directionally Solidified Vane Applications in Advanced Turbine Engines," Journal of Mat. Eng. and Perform., 2 (1993), p. 481-488 
14. Chang, J.C., et al., "Development of Microstructure and Mechanical Properties of a Ni-Base Single-Crystal Superalloy by Hot-Isostatic Pressing," Journal of Mat. Eng. and Perform., 12 (2003), p. 420-425.

15. R.C. Reed, D.C. Cox, and C.M.F. Rae, "Damage Accumulation During Creep Deformation of a Single Crystal Superalloy at $1150^{\circ} \mathrm{C}, "$ Mat. Sci. and Eng. A, 448 (2007), p. 88-96.

16. Defresne, A. and L. Remy, "Fatigue Behaviour of CMSX-2 Superalloy [001] Single Crystals at High Temperature 1: Low Cycle Fatigue of Notched Specimen,” Mat. Sci. and Eng. A, 129 (1990), p. 45-53.

17. Egly, T.A., et al., "Influence of Phase Shift and Strain Path on the Thermomechanical Fatigue Behavior of CMSX-4 Specimens, ” International Journal of Fatigue, 30 (2008), p. 249-256. 